\title{
Video-assisted thoracoscopic surgery lobectomy in lung cancer after neoadjuvant chemotherapy: feasibility and security analysis through video-assisted thoracoscopic surgery national registry data evaluation
}

\author{
Gino Zaccagna ${ }^{1}$, Carlo Zaraca ${ }^{1}$, Gabriella Di Leonardo ${ }^{1}$, Luca Bertolaccini ${ }^{2}$, Francesco Zaraca ${ }^{3}$, \\ Andrea De Vico ${ }^{1}$, Carlo Curcio ${ }^{4}$, Roberto Crisci ${ }^{1}$, Duilio Divisi ${ }^{1}$; Italian VATS Group* \\ ${ }^{1}$ Thoracic Surgery Unit, University of L’Aquila, “G. Mazzini” Hospital of Teramo, Teramo, Italy; ${ }^{2}$ Thoracic Surgery Unit, IEO, Milan, Italy; \\ ${ }^{3}$ Vascular and Thoracic Surgery, Bolzano, Italy; ${ }^{4}$ Thoracic Surgery Unit, "Monaldi” Hospital of Napoli, Napoli, Italy \\ Contributions: (I) Conception and design: D Divisi, R Crisci; (II) Administrative support: None; (III) Provision of study materials or patients: Italian \\ VATS Group; (IV) Collection and assembly of data: D Divisi, G Zaccagna; (V) Data analysis and interpretation: D Divisi, G Di Leonardo, L \\ Bertolaccini; (VI) Manuscript writing: All authors; (VII) Final approval of manuscript: All authors. \\ Correspondence to: Duilio Divisi, MD, PhD. Piazza Italia 1, 64100, Teramo, Italy. Email: duilio.divisi@aslteramo.it.
}

\begin{abstract}
Background: Lung cancer is the third most diagnosed tumor in Italy and is the leading cause of cancer death in males and the third in females. Video-assisted thoracoscopic surgery lobectomy (VATS-L) represents the gold standard for the treatment of early-stage non-small cell lung cancer (NSCLC). The aim of the study is to evaluate the short-and long-term outcomes of NSCLC patients with stage IIIA N2, treated with preoperative chemotherapy (CHT) followed by VATS lobectomy.
\end{abstract}

Methods: A retrospective analysis was performed on patients with NSCLC, who underwent VATS-L with (Group A) or without (Group B) neoadjuvant or induction CHT. Out of 6,846 patients enroled in the VATS Group National Registry, we selected 386 patients with stage IIIA NSCLC (pT1-2, N2). Forty-two patients (10.9\%) underwent neoadjuvant or induction CHT and then VATS-L (Group A). The remaining 344 patients $(89.1 \%)$ underwent VATS-L only (Group B).

Results: The outcomes evaluation between Group A and Group B showed respectively: (I) average length of stay, $9.4 v s .8 .5$ days; (II) average duration of pleural drainage, 4.7 vs. 4.6 days; (III) incidence of pneumonia, $4.8 \%$ vs. $4.1 \%$; (IV) mortality at 30 days, $0 \%$ vs. $0.3 \%$; (V) general mortality, $9.5 \%$ vs. $7.3 \%$; (VI) postoperative bleeding necessitating re-intervention and blood transfusion, $4.8 \%$ vs. $0.3 \%$ and $0 \%$ vs. $2.9 \%$; (VII) atrial fibrillation, $16.7 \%$ vs. $7.5 \%$; (VIII) prolonged air leaks, $11.9 \%$ vs. 7\%; (IX) respiratory failure, $0 \%$ vs. $0.3 \%$.

Conclusions: Our study confirms that VATS-L in patients with stage IIIA N2 NSCLC treated with neoadjuvant or induction CHT is feasible, oncologically effective and sufficiently safe.

\footnotetext{
* Italian VATS Group Collaborator List:

Mancuso M, Pernazza F, Refai M, Bortolotti L, Rizzardi G, Solli PG, Dolci GP, Perkmann R, Zaraca F, Benvenuti M, Gavezzoli D, CherchiR, Ferrari P, Mucilli F, Camplese P, Melloni G, Mazza F, Cavallesco G, Maniscalco P, Voltolini L, Gonfiotti A, Stella F, Argnani D. Pariscenti GL, Risso C, Surrente C, Lopez C, Droghetti A, Giovanardi M, Breda C, Lo Giudice F, Alloisio M, Bottoni E, Spaggiari L, Gasparri R, Torre M, Rinaldo A, Nosotti M, Tosi D, Negri GP, Bandiera A, Stefani A, Natali P, Scarci M, Pirondini E, Curcio C, Amore D, Baietto G, Rena O, Nicotra S, Dell'Amore A, Bertani A, Tancredi G, Ampollini L, Carbognani P, Puma F, Vinci D, Andreetti C, Poggi C, Cardillo G, Carleo F, Margaritora S, Meacci E, Luzzi L, Ghisalberti M, Crisci R, Zaccagna G, Lausi P, Guerrera F, Fontana D, Della Beffa V, Morelli A, Londero F, Imperatori A, Rotolo N, Terzi A, Viti A, Infante M, Benato C.
} 
Keywords: Advanced non-small cell lung cancer (NSCLC); video-assisted thoracoscopic surgery lobectomy (VATS-L); neoadjuvant chemotherapy (CHT); surgical treatment

Received: 04 December 2019; Accepted: 12 December 2019; Published: 25 May 2020.

doi: $10.21037 /$ ccts.2020.01.01

View this article at: http://dx.doi.org/10.21037/ccts.2020.01.01

\section{Introduction}

Lung cancer is still considered a "big killer" in Italy. According to the data from the Cancer Registry, it is the third most diagnosed male and female tumor, and is the leading cause of cancer death in sex male and the third in the female. The best treatment options are related to early diagnosis and surgical treatment. Radical surgery for curative purposes consists of resection associated with systematic lymph node dissection (LND). The traditional standard approach by thoracotomy have been replaced by video-assisted thoracoscopic surgery lobectomy (VATS-L) in the last twenty years, starting from early stages of lung cancer but currently also used in advanced cancers. Aim of the study was the feasibility and safety evaluation of VATS-L after neoadjuvant or induction chemotherapy (CHT) in patients with non-small cell lung cancer (NSCLC) at stage IIIA.

\section{Methods}

The data analyzed in this study were taken from the Italian VATS-Group Registry between January 2014 and December 2018. Criteria in order to be included in the database were as follows: (I) surgery performed exclusively by vision from the monitor; (II) main incision (utily incision) $<6 \mathrm{~cm}$ in diameter without costal gap; (III) 1 or 2 additional incisions (maximum $1 \mathrm{~cm}$ in diameter) can be made; (IV) single dissection of the hilar structures, associated with lymphadenectomy; (V) use of a dedicated bag (endobag) for sample extraction. The extent of lymphadenectomy is defined by the guidelines of the European Society of Thoracic Surgeons (ESTS) for intraoperative lymph node staging in NSCLC (1). A retrospective analysis was performed on IIIA NSCLC patients characterized by: (I) pT1a, b, c or pT2a, b (diameter of the primary lung tumor $<5 \mathrm{~cm}$ ); (II) pN2 (metastasis of mediastinal lymph nodes) and M0. Patients were classified in two Groups based on: (I) neoadjuvant or induction CHT, followed by minimally invasive lobectomy within 1 year of the first CHT (Group A); (II) VATS-L directly, without neoadjuvant or induction
CHT (Group B). Patient data included age, gender, Charlson comorbidity score and Eastern Cooperative Oncology Group (ECOG) comorbidity score $(2,3)$ and VATS lobectomy technique. The preoperative clinical stage was established by computed tomography (CT) scan, positron emission tomography-computed tomography (PET/CT) scanning, video-assisted mediastinoscopy (VAM), endobronchial ultrasound/transbronchial needle aspiration (EBUS/TBNA) or transesophageal endoscopic ultrasound/fine-needle aspiration (EUS/FNA). The lower limit of 75 total cases per structure in the analysis was used to include only the data coming from high-volume centers, excluding the beginner. Lymph node staging has been classified according to the guidelines of the European Society of Thoracic Surgeons (ESTS) (4). Perioperative complications have been defined as any deviation from the standard postoperative course within 30 days after the procedure and recorded according to the ClavienDindo classification $(5,6)$. The data of follow-up after discharge from the hospital were collected through direct check of patients or by the doctors who performed the last clinical control. In patients with N2 disease, re-staging after induction CHT and before resection was performed routinely. Intraoperative (operative time and conversion rate) and postoperative results (morbidity and mortality within 30 days, duration of chest drainage and length of stay) were analyzed. The extent of the lymphadenectomy was also evaluated. This study was conducted in accordance with the Declaration of Helsinki (as revised in 2013). The study was approved by the Italian VATS Group Scientific Committee and by the Ethics Committee of different hospitals. Individual informed consent was waived due to the retrospective nature of the study.

\section{Statistical analysis}

Continuous variables were reported as mean \pm standard deviation, while categorical variables were indicated as percentages. Student's test was used to compare continuous data. Pearson's tests and Fisher's exact test were used for 
Table 1 Patient characteristics

\begin{tabular}{|c|c|c|c|}
\hline Characteristics & Group A ( $n=42)$ & Group B $(n=344)$ & $P$ value \\
\hline Age, years & $67.4 \pm 8.3$ & $66.7 \pm 10.3$ & 0.69 \\
\hline FEV1 (mean \pm SD) (\% of predict) & $95.7 \pm 23.7$ & $93.8 \pm 19.6$ & 0.60 \\
\hline DLCO (mean \pm SD) (\% of predict) & $80.3 \pm 22.1$ & $81.4 \pm 24.1$ & 0.79 \\
\hline Renal disease (n, \%) & $0(0.0)$ & $15(4.4)$ & 0.54 \\
\hline COPD (n, \%) & $9(21.4)$ & $83(24.1)$ & 0.69 \\
\hline Vascular disease $(\mathrm{n}, \%)$ & $9(21.4)$ & $49(14.2)$ & 0.047 \\
\hline Congestive heart failure (n, \%) & $1(2.4)$ & $9(2.6)$ & 0.92 \\
\hline History of cigarettes smoking (n, \%) & NA & NA & - \\
\hline Previous extrathoracic malign neoplasia (n, \%) & $0(0.0)$ & $7(2.0)$ & 0.88 \\
\hline
\end{tabular}

FEV1, forced expiratory volume in 1 second; DLCO, diffusion lung carbon monoxide; COPD, chronic obstructive pulmonary disease.

categorical variables. Univariate analysis was performed on selected variables. The resulting significant variables at the 0.30 level were included in a Cox multivariate logistic regression model. Statistical significance was set at 0.05 . Statistical analysis was performed using SPSS 24.0 (SPSS Inc., Chicago, IL, USA) and R 3.3.1 (R Core Team, 2016).

\section{Results}

Of 6,846 patients enrolled in the VATS Group National Registry at the time of extrapolation of the data, we selected 386 NSCLC patients with postoperative IIIA histological staging (pT1-2, N2). Only $10.9 \%$ of these (42 cases) underwent neoadjuvant or induction CHT and then VATS-L (Group A) while the remaining 344 (89.1\%) patients underwent VATS-L without CHT (control B Group) (Table 1). The indication for neoadjuvant treatment in Group A was the metastasis to N2 lymph nodes (ipsilateral mediastinal and tracheal carina) diagnosed by: (I) conventional transbronchial needle aspiration (TBNA) in $57.2 \%(\mathrm{n}=24)$ of patients; (II) endobronchial ultrasound/ transbronchial needle aspiration (EBUS) in $35.7 \%(\mathrm{n}=15)$ of patients; (III) mediastinoscopy in $7.1 \%(\mathrm{n}=3)$ of patients. Regarding the pathological N2 staging, the comparison between Group A and Group B highlighted: (I) positive station 2 (upper paratracheal) lymph nodes in 9 of 42 patients $(21.4 \%)$ vs. 26 of 344 patients $(7.6 \%, \mathrm{P}=0.003)$; (II) positive station 3 (pre-vascular and retrotracheal) lymph nodes in 0 of 42 patients $v s .4$ of 344 patients $(1.2 \%$, $\mathrm{P}=0.50$ ); (III) positive station 4 (lower paratracheal) lymph nodes in 23 of 42 patients (54.8\%) vs. 115 of 344 patients (33.4\%, $\mathrm{P}=0.006$ ); (IV) positive station 5 (subaortic) lymph nodes in 1 patient of 42 (2.4\%) vs. 82 of 344 patients $(23.8 \%$, $\mathrm{P}=0.001) ;(\mathrm{V})$ positive station 6 (para-aortic) lymph nodes in 2 of 42 patients (4.8\%) vs. 29 of 344 patients $(8.4 \%$, $\mathrm{P}=0.40$ ); (VI) positive station 7 (subcarinal) lymph nodes in 23 of 42 patients $(54.8 \%)$ vs. 146 of 344 patients (42.4\%, $\mathrm{P}=0.12$ ); (VII) positive station 8 (paraesophageal) lymph nodes in 3 of 42 patient (7.1\%) vs. 30 of 344 patients (8.7\%, $\mathrm{P}=0.72$ ); (VIII) positive station 9 (pulmonary ligament) lymph nodes in 1 of 42 patients (2.4\%) vs. 20 of 344 patients $(5.8 \%, \mathrm{P}=0.35)$. The incidence of metastases at multiple lymph node stations was statistically higher in Group A (20 of 42 patients, $47.6 \%$ ) than Group B (108 of 344 patients, $31.4 \%)(\mathrm{P}=0.03)$. About the histology, 31 Group A patients (73.8\%) displayed an adenocarcinoma vs. 281 Group B patients $(81.7 \%)(\mathrm{P}=0.22)$ while squamous cell carcinoma histotype was found mostly in Group A (10 patients, 23.8\%) compared to Group B (37 patients, $10.8 \% ; \mathrm{P}=0.014)$. Other subtypes such as large cell carcinoma, carcinoid tumors and pleomorphic carcinoma were found only in Group B at the rate of $0.6 \%$ ( 2 patients, $\mathrm{P}=0.20$ ), $3.2 \%$ (11 patients, $\mathrm{P}=0.77$ ) 


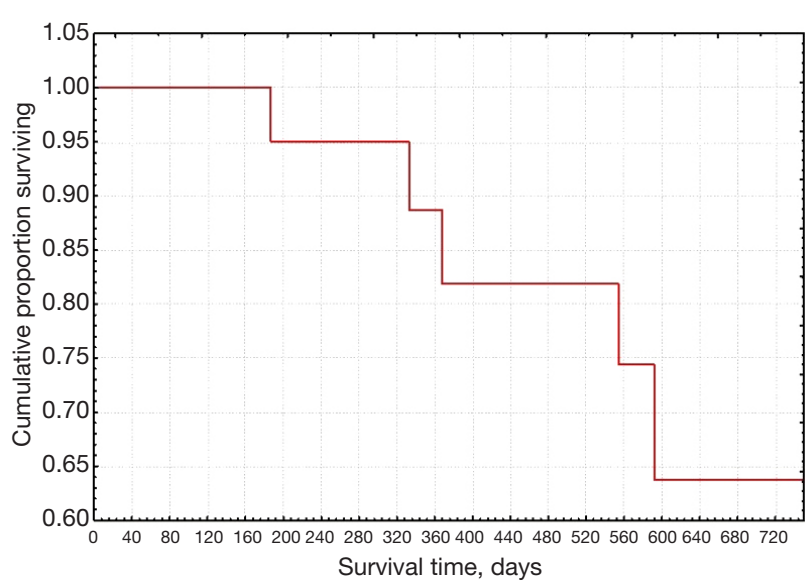

Figure 1 Incidence of recurrence.

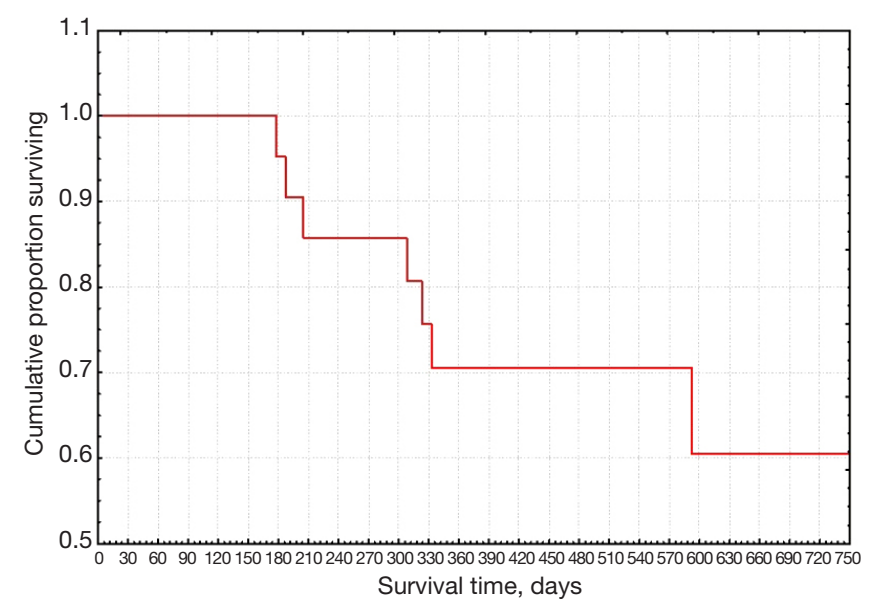

Figure 2 Survival curve.

and $0.6 \%$ ( 2 patients, $\mathrm{P}=0.20$ ) respectively. Short-term perioperative outcomes were monitored in both Groups and the collected data were the following: (I) average length of hospital stay, 9.4 days in Group A vs. 8.5 days in group $\mathrm{B}(\mathrm{P}=0.32)$; (II) average length of chest drainage, 4.7 days in Group A vs. 4.6 days in Group B $(\mathrm{P}=0.91)$; (III) rate of pneumonia, $4.8 \%$ in Group A (2 of 42 patients) vs. $4.1 \%$ in Group B (14 of 344 patients; $\mathrm{P}=0.83$ ); (IV) 30-day mortality, $0 \%$ in Group A vs. $0.3 \%$ in Group B (1 of 344 patients) $(\mathrm{P}=0.75) ;(\mathrm{V})$ overall mortality, $9.5 \%$ in Group A (4 of 42 patients) vs. $7.3 \%$ in Group B (25 of 344 patients) ( $\mathrm{P}=0.60)$; (VI) postoperative bleeding requiring reoperation, $4.8 \%$ in Group A ( 2 of 42 patients) vs. $0.3 \%$ in Group B (1 of 344 patients) $(\mathrm{P}=0.001)$; (VII) postoperative bleeding requiring blood transfusion, $0 \%$ in Group A vs. 2.9\% in Group B (10 of 344 patients) ( $\mathrm{P}=0.84)$; (VIII) atrial fibrillation, $16.7 \%$ in Group A (7 of 42 patients) vs. $7.5 \%$ in Group B (26 of 344 patients) ( $\mathrm{P}=0.04)$; (IX) prolonged air leaks, $11.9 \%$ in Group A (5 of 42 patients) vs. 7.0\% in Group B (24 of 344 patients) $(\mathrm{P}=0.25)$; $(\mathrm{X})$ respiratory failure, $0 \%$ in Group A vs. $0.3 \%$ in Group B (1 of 344 patients) $(\mathrm{P}=0.75)$; (XI) other complications (myocardial ischemia, ictus, pulmonary embolism) $0 \%$ in Group A vs. 6.7\% in Group B, (23 of 344 patients) $(\mathrm{P}=0.27)$. Conversion from VATS-L to open thoracotomy were $14.3 \%$ in Group A (6 of 42 patients) vs. $11.3 \%$ in Group B (39 of 344 patients) $(\mathrm{P}=0.57)$; no conversion was due to difficulty in performing dissection linked to fibrous tissue in patients undergoing neoadjuvant treatment. The reasons for conversion in Group A (6 patients) and in Group B (39 patients) were respectively: (I) pleuroparenchymal adhesions, 3 patients $(50 \%) v s$. 11 patients (28.2\%); (II) bleeding, 1 patient (16.7\%) vs. 11 patients $(28.2 \%)$; (III) difficulty in pulmonary artery dissection due to calcific perivascular lymph nodes, 1 patient (16.7\%) vs. 13 patients (33.3\%); (IV) anomaly in anatomy, 1 patient (16.7\%) vs. 4 patients (10.3\%).

\section{Survival analysis}

In regard to the analysis of survival, we have extrapolated the data relating to the follow-up of Group A in the 5-year timeframe from 2014 to 2019 . The relapses showed a maximum probability level in the first follow-up period (about 180 days) and then decrease over time until reaching a stability after one year (Figure 1). Survival according to the Kaplan-Meier test decreased over time, with a high rate in the first year and remaining still higher than 0.5 even at the end of the follow-up (Figure 2).

\section{Discussion}

In recent years we observed a continuous expansion of VATS-L indications. Neoadjuvant CHT followed by a VATS-L in patients at stage IIIA N2 NSCLC represents one of the most interesting research frontiers not yet fully explored in the literature (7-11). Mollberg et al. (12) analyzed 65 patients with NSCLC larger than $2 \mathrm{~cm}$ in stage III, N2. After neoadjuvant CHT, patients were re-staged with PET/CT and underwent VATS-L only if no signs of disease progression were found. Although the Authors defined some contraindications to VATS-L, such as the infiltration of the chest wall by the tumor or the presence of calcifications near the pulmonary artery, the study did not draw conclusions on the safety and efficacy of VATS-L 
after neoadjuvant CHT due to the low number of patients examined. Huang et al. (13) retrospectively studied 42 patients undergoing induction therapy (CHT in 27 patients and CHT + RT followed by VATS resection in 16 patients) diagnosed at stage IIIA in most of them $(63 \%)$. Thirtythree patients $(77 \%)$ underwent lobectomy or bilobectomy, 4 patients (9\%) pneumonectomy and 5 patients (12\%) wedge resection. The total complication and mortality rate were $12 \%$ and $2 \%$ respectively but these parameters were not stratified according to the extent of resection or the type of induction therapy. Petersen et al. (14) examined outcomes in 97 patients undergone induction therapy followed by pulmonary resection, comparing VATS-L (8 patients received induction CHT + RT while 4 patients received CHT alone) versus open lobectomy (85 patients). Both Groups were homogeneous about demographic characteristics, lung function, comorbidities, factor $\mathrm{T}$ and $\mathrm{N}$. No significant difference between the two groups was found as regards the number of lymph nodes removed, the 30-day mortality rate, major complications, overall survival and 2 years recurrences. However, VATS-L patients displayed a statistically shorter average length of hospital stay (3.5 vs. 5 days) and of chest drainage (2 vs. 4 days). Yang et al. (15) studied 272 patients undergoing induction therapy followed by VATS (69 patients) or thoracotomy (203 patients) lobectomy. Authors found no statistically significant difference in the thirty-day mortality between the two groups: VATS $3 \%$ vs. open $4 \%(\mathrm{P}=0.69)$. The 3 -year survival of VATS was better than that of thoracotomy ( $61 \%$ vs. $43 \%, \mathrm{P}=0.010$ ), with a tendency towards survival improvement only in VATS patients (hazard ratio, 0.56; $95 \%$ confidence interval, $0.32-1.01 ; \mathrm{P}=0.053)$. Authors concluded that neoadjuvant CHT should not be considered a contraindication to VATS-L in patients with advanced NSCLC. In our experience, the comparison between Group A and Group B showed a greater number T2b N2 patients with frequent involvement of 2 and 4 ipsilateral lymph node station. In contrast, Group B highlighted a greater infiltration of the 5 lymph node stations. This statistically significant difference $(\mathrm{P}=0.001)$ can be ascribed to a better and easier preoperative evaluation of stations 2 and 4 compared to station 5 by endobronchial - esophageal ultrasound or VAM, with reduced risk of lung cancer upstaging or downstaging and focused treatment strategy. Group A compared to Group B also displayed a higher postoperative percentage of bleeding and atrial fibrillation, with statistical significance. Evidently, VATS-L after neoadjuvant CHT was burdened by an alteration of platelet activity (16-19) and of electrical stimulation of the heart probably due to risk factors and systemic inflammation (20-23). The coagulation mechanisms depend on a balance between thrombotic and anti-thrombotic factors. In cancer patients, the reduced levels of coagulation inhibitors, antiphospholipid antibodies and tumor-derived tissue factor (TF) determine an alteration of fibrinolysis and activated protein C linked to the hypercoagulation. Obviously, postoperative disseminated intravascular coagulation may more easily occur with platelet consumption and bleeding. Coagulation disorders are also accentuated by diabetes, which we found in many patients in the two Groups. These clinical situations require reoperation and new coagulation set-up as blood transfusions may not be enough (17-19). Several studies in literature displayed a correlation between CHT and atrial fibrillation (FA). Xie et al. (20) analyzed 144 patients carried out thoracotomy. Eighteen patients showed postoperative FA, 7 of which (38.9\%) undergone neoadjuvant CHT. One hundred twenty-six patients did not develop FA, 19 of which (15.1\%) undergone neoadjuvant CHT. Guglin et al. (21) examined the published papers on arrhythmias due to CHT, using the PubMed/Medline and OVID databases from 1,950 onwards to better understand this correlation. Particularly, cisplatin and melfalan are associated with $\mathrm{FA}$ rates ranging from $12 \%$ to $32 \%$ and from $7 \%$ to $12 \%$ respectively. However, the development of atrial fibrillation could depend on a structural and electrical myocardial remodeling and not just from CHT (22). Also, we revealed more chronic obstructive pulmonary disease (COPD) patients in Group A than Group B. Correlation between COPD and atrial fibrillation has already wide studied in literature $(23,24)$. Konecny et al. (25), analyzing data from 7441 patients who undergone pulmonary function tests and 24-hour Holter, showed 3121 COPD patients (41.9\%). These patients, compared to those without COPD, developed FA $(23.3 \%$ vs. $11.0 \%, \mathrm{P}<0.0001)$ and ventricular tachycardia $(13.0 \%$ vs. $5.9 \%$ respectively, $\mathrm{P}<0.0001)$ more easily.

\section{Conclusions}

In conclusion, our study confirmed that VATS-L in stage IIIA N2 non-small cell lung cancer patients treated with neoadjuvant $\mathrm{CHT}$ is feasible, oncologically effective and sufficiently safe. However, should be considered the high postoperative risk of major bleeding and atrial fibrillation, requiring compliance with the international guidelines for high-risk patients in order to prevent these complications. 


\section{Acknowledgments}

Funding: None.

\section{Footnote}

Provenance and Peer Review: This article was commissioned by the Guest Editors (Francesco Zaraca, Reinhold Perkmann, Luca Bertolaccini and Roberto Crisci) for the series "Thoracic Surgery Without Borders" published in Current Challenges in Thoracic Surgery. The article has undergone external peer review.

Conflicts of Interest: All authors have completed the ICMJE uniform disclosure form (available at https://ccts. amegroups.com/article/view/10.21037/ccts.2020.01.01/ coif). The series "Thoracic Surgery Without Borders" was commissioned by the editorial office without any funding or sponsorship. LB, FZ and RC serve as the unpaid Guest Editors of the series. The authors have no other conflicts of interest to declare.

Ethical Statement: The authors are accountable for all aspects of the work in ensuring that questions related to the accuracy or integrity of any part of the work are appropriately investigated and resolved. The study was conducted in accordance with the Declaration of Helsinki (as revised in 2013). The study was approved by the Italian VATS Group Scientific Committee and by the Ethics Committee of different hospitals. Individual informed consent was waived due to the retrospective nature of the study.

Open Access Statement: This is an Open Access article distributed in accordance with the Creative Commons Attribution-NonCommercial-NoDerivs 4.0 International License (CC BY-NC-ND 4.0), which permits the noncommercial replication and distribution of the article with the strict proviso that no changes or edits are made and the original work is properly cited (including links to both the formal publication through the relevant DOI and the license). See: https://creativecommons.org/licenses/by-nc-nd/4.0/.

\section{References}

1. Lardinois D, De Leyn P, Van Schil P, et al. ESTS guidelines for intraoperative lymph node staging in non-small cell lung cancer. Eur J Cardiothorac Surg
2006;30:787-92.

2. Charlson ME, Pompei P, Ales KL, et al. A new method of classifying prognostic comorbidity in longitudinal studies: development and validation. J Chronic Dis 1987;40:373-83.

3. Oken MM, Creech RH, Tormey DC, et al. Toxicity and response criteria of the Eastern Cooperative Oncology Group. Am J Clin Oncol 1982;5:649-55.

4. Liu Y, Gao Y, Zhang H, et al. Video-assisted versus conventional thoracotomy pneumonectomy: a comparison of perioperative outcomes and short-term measures of convalescence. J Thorac Dis 2016;8:3537-42.

5. Seely AJ, Ivanovic J, Threader J, et al. Systematic Classification of Morbidity and Mortality After Thoracic Surgery. Ann Thorac Surg 2010;90:936-42.

6. Dindo D, Demartines N, Clavien PA. Classification of surgical complications: a new proposal with evaluation in a cohort of 6336 patients and results of a survey. Ann Surg 2004;240:205-13.

7. Shaw JP Dembitzer FR, Wisnivesky JP, et al. VideoAssisted Thoracoscopic Lobectomy: State of the Art and Future Directions. Ann Thorac Surg 2008;85:S705-9.

8. Hennon M. Sahai RK, Yendamuri S, et al. Safety of thoracoscopic lobectomy in locally advanced lung cancer. Ann Surg Oncol 2011;18,3732-6.

9. Yang CF, Adil SM, Anderson KL, et al. Impact of patient selection and treatment strategies on outcomes after lobectomy for biopsy-proven stage IIIA pN2 nonsmall cell lung cancer. Eur J Cardiothorac Surg 2016; 49:1607-13.

10. Yang Z, Zhai C. Uniportal video-assisted thoracoscopic surgery following neoadjuvant chemotherapy for locallyadvanced lung cancer. J Cardiothorac Surg 2018;13:33.

11. Yan TD, Black D, Bannon PG, et al. Systematic Review and Meta-Analysis of Randomized and Nonrandomized Trials on Safety and Efficacy of Video-Assisted Thoracic Surgery Lobectomy for Early-Stage Non-Small-Cell Lung Cancer. J Clin Oncol 2009;27:2553-62.

12. Mollberg NM, Mulligan MS. Video-Assisted Thoracoscopic (VATS) Lobectomy After Induction Therapy. Thorac Surg Clin 2014;24:465-70.

13. Huang J, Xu X, Chen H, et al. Feasibility of complete video-assisted thoracoscopic surgery following neoadjuvant therapy for locally advanced non-small cell lung cancer. J Thorac Dis 2013;5 Suppl 3:S267-73.

14. Petersen RP, Pham D, Toloza EM, et al. Thoracoscopic Lobectomy: A Safe and Effective Strategy for Patients Receiving Induction Therapy for Non-Small Cell Lung 
Cancer. Ann Thorac Surg 2006;82:214-8.

15. Yang CF, Meyerhoff RR, Mayne NR, et al. Long-term survival following open versus thoracoscopic lobectomy after preoperative chemotherapy for non-small cell lung cancer. Eur J Cardiothorac Surg 2016;49:1615-23.

16. Frendl G, Sodickson AC, Chung MK, et al. 2014 AATS guidelines for the prevention and management of perioperative atrial fibrillation and flutter for thoracic surgical procedures. J. Thorac Cardiovasc Surg 2014;148:e153-93.

17. Zhu YW, Feng TB, Zhou XJ, et al. Routine Hemostasis and Hemogram Parameters: Valuable Assessments for Coagulation Disorder and Chemotherapy in Cancer Patients. Chin Med J (Engl) 2016;129:1772-7.

18. Khorana AA, Connolly GC. Assessing risk of venous thromboembolism in the patient with cancer. J Clin Oncol 2009;27:4839-47.

19. Wang Z, Dang C, Zhu K, et al. Cyclophosphamide, epirubicin and fluorouracil chemotherapy-induced alteration of haemostasis markers in breast cancer patients. Mol Clin Oncol 2015;3:1088-92.

doi: $10.21037 /$ ccts.2020.01.01

Cite this article as: Zaccagna G, Zaraca C, Di Leonardo G, Bertolaccini L, Zaraca F, De Vico A, Curcio C, Crisci R, Divisi D; Italian VATS Group. Video-assisted thoracoscopic surgery lobectomy in lung cancer after neoadjuvant chemotherapy: feasibility and security analysis through video-assisted thoracoscopic surgery national registry data evaluation. Curr Chall Thorac Surg 2020;2:15.
20. Xie K, Zhang W, Fang J, et al. Prevalence and risk factors of atrial fibrillation during lung and esophageal surgery: A Prospective observational study. Medicine (Baltimore) 2018;97:e11549.

21. Guglin M, Aljayeh M, Saiyad S, et al. Introducing a new entity: chemotherapy-induced arrhythmia. Europace 2009;11:1579-86.

22. Zaman JAB, Harling L, Ashrafian H, et al. Post-operative atrial fibrillation is associated with a pre-existing structural and electrical substrate in human right atrial myocardium. Int J Cardiol 2016;220:580-8.

23. Goudis CA. Chronic obstructive pulmonary disease and atrial fibrillation: An unknown relationship. J Cardiol 2017;69:699-705.

24. Shibata, Y, Watanabe T, Osaka D, et al. Impairment of pulmonary function is an independent risk factor for atrial fibrillation: the Takahata study. Int J Med Sci 2011;8:514-22.

25. Konecny T, Park JY, Somers KR, et al. Relation of chronic obstructive pulmonary disease to atrial and ventricular arrhythmias. Am J Cardiol 2014;114:272-7. 